\title{
Assistência Psicossocial como coadjuvante na Redução da Depressão em Idosos
}

\author{
Laís Leite Fernandes ${ }^{1}$; Marianna Leite Barroso ${ }^{2}$; Ana Olívia de Oliveira Marinho ${ }^{3}$; Solange Gonçalves Rolim ${ }^{4}$; \\ Bernadete Souza Silva ${ }^{5}$
}

\begin{abstract}
Resumo: A população com mais de sessenta anos tem crescido nos últimos anos, bem como uma série de doenças próprias dessa faixa etária, tal como a depressão. Esta doença tem se consolidado como um dos grandes problemas de saúde pública mundial, devido à sua alta taxa de morbimortalidade. Diversas são as enfermidades associadas, desde a perda de peso, sentimentos de culpa, acompanhados ou não de ideação suicida, hipocondria e queixas diversas de dores, o que prejudica em muito a qualidade de vida dessa parcela da população. Outro aspecto relevante é que, o declínio se apresenta bem mais acentuado em pessoas deprimidas idosas, do que em pessoas deprimidas mais jovens, assim como a baixo condicionamento cardiorrespiratório. Este estudo visa discutir questões relativas ao idoso, bem como demonstrar a importância de uma assistência Psicossocial como coadjuvante na redução da depressão em pessoas idosas.
\end{abstract}

Palavras-chave: Depressão, Idoso, Assistência Psicossocial

\section{Psychosocial as an adjunct to Reduce Depression in Elderly}

\begin{abstract}
The population over sixty years has grown in recent years as well as a number of diseases typical of this age group, such as depression. This disease has been established as a major public health problem worldwide, due to its high mortality rate. Several diseases are associated, from weight loss, feelings of guilt , with or without suicidal ideation, hypochondriasis and several complaints of pain, which hurts a lot the quality of life in this part of the population. Another relevant aspect is that the decline appears much more pronounced in older depressed people, depressed people than in younger as well as low cardiorespiratory fitness . This study aims to discuss issues relating to the elderly, as well as demonstrating the importance of psychosocial care as an adjunct in reducing depression in older people.
\end{abstract}

Keywords: Depression, Elderly, Psychosocial

\footnotetext{
${ }^{1}$ Enfermeira pela Universidade Regional do Cariri - URCA. Enfermeira Técnica e Consultora da Empresa Provida Medical. Enfermeira Hemodinamicista da Casa de Saúde e Maternidade São Miguel. E-mail: laisenfr@hotmail.com;

${ }^{2}$ Enfermeira. Mestranda em Saúde pública pela Universidade Tecnológica Intercontinental - UTIC/PY. E-mail: mariannaleite_@hotmail.com;

${ }^{3}$ Acadêmica de Medicina pela Universidade de Pernambuco - UPE. E-mail: fantinhapx@gmail.com;

${ }^{4}$ Psicóloga pela Universidade Federal da Paraíba, atuando nas áreas Clínica e Organizacional. E-mail: solange-grolim@ig.com.br.

${ }^{5}$ Economista pela Universidade Regional do Cariri - URCA; Pós graduada em Administração de Empresas (URCA). Especializanda em Gerontologia pela FJN. Psicóloga pela Faculdade Leão Sampaio - CE. E-mail: bernassilva@ yahoo.com.br
} 


\section{Introdução}

As pessoas idosas, isto é, com mais de 60 anos de idade são, atualmente , o grupo etário que mais tem crescido em todo o mundo. As estimativas para 2025, nos informam um crescimento, em termos percentuais, ainda maior que o atual (OMS, 1999) .

Segundo a Organização Mundial de Saúde (2000), nos Estados Unidos, já existem mais velhos do que crianças com até 10 anos de idade. Em outros países europeus como Portugal, França e Gran-Bretanha, também há um incremento no número de pessoas idosas, anualmente.

Estes dados, referentes aos Estados Unidos e as três outros países que, na Europa, representam os dois extremos do desenvolvimento, dão-nos uma idéia aproximada do que acontece, ou irá acontecer, em data não muito distante por todo o mundo. No Brasil, os aproximadamente 8,5 milhões de pessoas hoje com mais de 60 anos, constituem cerca de 7\% da população (BRASIL, 2010).

Na cidade de Barbalha, universo da nossa pesquisa, estima-se haver, aproximadamente três mil idosos acima de 60 anos (Dados fornecidos pelo Conselho Municipal de Assistência Social de Barbalha/2010)

Técnicos de vários ramos de ciências humanas e organismos políticos nacionais e internacionais interrogam-se sobre essa mudança, que está ainda longe de alcançar o ponto culminante. Até onde poderá ir e, a que imprevisíveis situações a ascendente curva dos velhos levará a humanidade com os êxitos da ciência, no prolongamento da vida e do índice de natalidade em progressão descendente? O envelhecimento porcentual das populações na segunda metade desse século tem sido inquietante do ponto de vista econômico e social.

Antes da sociedade industrial, os velhos, os adultos de meia-idade e os jovens constituíam agregados familiares coesos e estáveis, apoiados por fatores decorrentes de uma economia agrícola em que todos colaboravam. A comunhão das gerações se dava pela necessidade. Agora, sem os vínculos ditados por um trabalho comum, ela deverá ser alcançada mediante opções livres, nem sempre fáceis, de velhos e jovens, o que implica tornar-se mais humana, mais nobre e menos um produto de circunstâncias do meio ambiente. Embora seja grave o risco que correm os anciãos de se verem, nos próximos anos, postos à margem das preocupações do grande mundo, cada vez mais corroído pela atração da riqueza e do prazer, a longo prazo, a questão pode ser vista de ângulos bem diferentes, tendo em vista o fortalecimento do poder político (em número) das pessoas idosas.

No que diz respeito a melhoria de vida e a longividade, começam a surgir indícios, após recentes experiências realizadas em Oxford têm obtido resultados importante com relação a cura de diversos casos de paralisia, de cegueira e de outras moléstias causadas por deficiências do sistema nervoso central (WOLF, 2001).

Id en line Revista de Psicologia. Ano 7, No. 21, Novembroo/2013 - ISSN 1981-1179.

Edição eletrônica em http://idonline.emnuvens.com.br/id 
As pesquisas genéticas envolvendo células -tronco são uma realidade. Com a expectativa inclusive, de se conhecer melhor o código genético que determina o processo de envelhecimento do corpo humano, abrindo caminho para invenção de drogas que, interfiram, retardando-o, nesse processo. Dessa forma, quatro ou mais gerações poderiam então conviver em uma mesma época (OMS. 2001).

Talvez tudo isso pareça um tanto utópico, quando imaginamos que, em meados do século XX, a expectativa de vida era de 48 anos nos países ricos. Hoje beira-se os 80 anos ou mais, mesmos países.

É impossível saber o peso efetivo que esta situação provocará. E, se as pessoas idosas e terão melhor ou pior acolhimento do que hoje, pois, sem dúvida, serão mais numerosas. Se a democracia, como se crê, for o regime então dominante, e os cidadãos comuns, em vez dos tecnocratas, puderem escolher as regras do jogo, os velhos deveriam exercer na política uma influência decisiva. $\mathrm{O}$ crescimento desta influência poderia ser, uma constante no avanço dos povos, para o progresso.

A mentalidade corrente, nos países capitalistas, que chega a considerar os velhos indesejáveis, em nada contribui para melhorar a situação dos mesmos. Evita-se em usar o termo "velho"; ou seu sinônimo "ancião", preferindo-se falar em "terceira idade", enquanto não chega o dia em que esta expressão se torne, pelo uso e pela consciência dos motivos que levaram a torná-la, ainda mais incomodativa.

Nem a Pastoral Cristã conseguiu vencer toda a influência desta mentalidade, e assistimos a uma diminuída atenção dirigida aos velhos, que tanto necessitam do conforto e estímulo que só a religião lhe oferece. Às crianças, aos jovens, aos casais, aos adultos em plena atividade profissional, dedica-se um esforço de evangelização dia a dia mais especializado. Pelos idosos pouco se tem feito, em termos de renovação, salvo a boa vontade de certas iniciativas beneméritas, de amplitude muito mais restrita do que as suas congêneres voltadas para outras faixas etárias.

Atualmente já é grande o acúmulo de informações científicas sobre a psicologia dos anciãos, tendo aparecido nos últimos 50 anos, várias publicações de pesquisadores interessados na matéria. Mas durante muito tempo, a ciência, que dava tanta atenção à psicologia de outros segmentos da sociedade, ignorou os velhos e os seus problemas (WHO,2005). É lamentável que, determinados estudos da psicologia e da psiquiatria tenham esquecido as pessoas idosas, num gênero de pesquisa que tanto tem a ver com educação. Por um lado, a idéia de educação para idosos parecia um tanto estranha. Por outro, a polêmica gerada em torno da origem dos distúrbios psíquicos demorou a abrir caminhos ao reconhecimento da influência dos fatores emocionais naqueles distúrbios, que muitas vezes complicam a vida dos anciãos.

O conceito desfavorável que se faz da velhice é de natureza emocional, pois a razão, aponta noutro sentido. É uma sobrevivência, digna de todo apreço, de outra mentalidade, que se espera venha 
de novo triunfar, como o uso que se faz no Brasil da palavra "velho" em expressões como "meu velho", dirigida com evidente tom afetivo ao pai ou a um grande amigo.

A permanência dos anciãos na família concorre eficazmente para o equilíbrio de todos os que a constituem: dará aos jovens o exemplo vivo da importância dos valores espirituais, religiosos e humanos e evitará que se perca a idéia da limitação temporal da existência, o que é de suma utilidade no campo da sabedoria prática. Já no livro do profeta Zacarias aparece como dádiva de Deus o benefício do convívio das gerações: "Nas praças de Jerusalém voltarão a ver-se sentados velhos e velhas, cada um apoiado em seu bastão por causa da muita idade. As praças da cidade encher-se-ão de meninos e meninas, que virão aí brincar". Este era o pensamento sustentado por antigas civilizações. Hoje em países como a Grã-Betanha, é corrente o absurdo pedagógico de não ser aconselhável a convivência de crianças com idosos, pelo que, dizia-se num programa da BBC em 4 de julho de 2009 , se requerem para estes mais centros de convívio e mais camas nos hospitais, a ponto de o Serviço Nacional de Saúde dispor de verbas para satisfazer a intensa demanda.

Dirigindo-se para as mulheres viúvas, numa mensagem datada de 17 de maio de 1982, lamentava o Papa João Paulo II:

Demasiadas vezes se verifica, sobretudo nos países ricos, a triste situação das viúvas idosas que, não podendo já ficar na casa dos filhos, passam os últimos anos na solidão, entrecortada por raras visitas, mesmo que sejam confortáveis as casas de velhos que os recolhem.

Dentre os problemas da terceira idade, uma doença grave. A depressão, que vitima uma parcela significativa dessa população, e que tem em seu quadro de sintomas até mesmo o desejo da morte.

A depressão tem se consolidado como um dos grandes problemas de saúde pública mundial, devido à sua alta taxa de morbimortalidade (STRAWBRIDGE, DELEGER, ROBERTS, KAPLAN, 2002) . Nos EUA, tem atingido cerca de 9,5\% dos adultos por ano. Sua incidência na população mundial chega a aproximadamente 17\% (DAVIDSON, LEWIS, ALLOY, AMARAL, BUSH, COHEN, et AL, 2002). Dentre as suas principais características, encontram-se a perda de peso, os sentimentos de culpa, a ideação suicida, a hipocondria, as queixas de dores diversas e, eventualmente, a psicose. Quando se trata de pessoas idosas, esses sintomas se apresentam bem mais acentuados em pessoas deprimidas idosas, do que em pessoas deprimidas mais jovens. Contribuem para um real declínio cognitivo (YAFFE, BLACKWELL, GORE, SANDS, REUS, BROWNER, 1999) e do condicionamento cardiorrespiratório (HOLLENBERG, HAIGHT, TAGER, 2003), quando nessa faixa etária.

Id en line Revista de Psicologia. Ano 7, No. 21, Novembroo/2013 - ISSN 1981-1179

Edição eletrônica em http://idonline.emnuvens.com.br/id 
De acordo com a professora do Departamento de Saúde Comunitária da Faculdade de Medicina da Universidade Federal do Ceará, Dra. Gislene Farias de Oliveira,

As pessoas com depressão tem reportado uma sensação extremamente desagradável, porém, os pacientes, principalmente os anciãos, nem sempre conseguem localizar o problema. Têm dificuldade de revelar o que realmente estão sentindo, a exemplo da tristeza, das perdas e dos problemas emocionais. Geralmente os doentes queixam-se de problemas físicos, enquanto os médicos, quase sempre, esperam sintomas clínicos. Dessa forma, torna-se comum uma certa indignação frente à doença, tanto por parte dos doentes, quanto pelos familiares. Acontecem casos até de suicídio, antes mesmo de se buscar algum tipo de ajuda, muitas vezes, poucas semanas da instalação do quadro depressivo.

A frequência do uso de antidepressivos está abaixo da prevalência da doença, pois, os médicos clínicos, em geral, não diagnosticam vários quadros depressivos, confundindo-os com outros sintomas. Mesmo assim, pesquisas mundiais revelam que $95 \%$ dos casos de depressão são tratados pelo clínico geral (VERAS, 1994).

A melancolia, estado de profunda depressão costuma aparecer justamente em pessoas idosas, que são comumente tratados com antidepressivos. Essas substâncias não conseguem modificar o estado emocional subjacente, mas simplesmente aliviam por algum tempo a sintomatologia da depressão nos casos mais agudos.

A depressão profunda, nos idosos, pode ser um sintoma de perturbações emocionais, sentimentos de culpa e de rejeição, ou problemas mentais, onde os antidepressivos conseguem criar um estado de espírito mais favorável e permitir-lhe que reaja melhor a qualquer tratamento. A combinação ideal do recurso humano e dos antidepressivos é fundamental para o tratamento da depressão (VERAS, 1994).

A incidência da depressão não pode ser corretamente estimada, em virtude das dificuldades na sua definição, reconhecimento, investigação e "denúncia" aos órgãos competentes.

Campos et al (1995), comentam que, a contribuição da ciência e mesmo dos organismos estatais ou religiosos seria de pouca eficácia, caso os próprios idosos não procurassem ajudar-se, na medida do possível, a também resolverem os seus problemas. As reformas, que por ventura venham a acontecer nas sociedades, não dizem respeito àquilo que os governos devem promover em favor dos idosos, mas trata-se de um trabalho conjunto, onde os próprios envolvidos têm um papel fundamental, no fazer por si próprios. Se os idosos não se reabilitarem diante de si mesmos, tornar-se-á mais difícil a reabilitação perante o social.

Neste sentido, é necessário, por parte do idoso e/ou do seu cuidador responsável, um empenho pessoal, em vez de proteção e, de responsabilidade, em vez de paternalismo. Na ação política e na 
pastoral religiosa, que visam melhorar a situação dos velhos, esta atitude é primordial. Não se pode perder mais tempo a lamentar, o fato de não se criar os meios para uma digna integração social para essa faixa etária.

A falta de informações sobre os sintomas e preconceitos em relação ao tratamento da depressão é alta. Em torno de 3\% dos brasileiros. As taxas de suicídio tem aumentado entre os idosos, principalmente nas metrópoles. Segundo a Revista Médica Prodoctor (1996, no. 61), a população adulta sofreria pelo menos uma crise depressiva a cada ano, com características significantes e episódios depressivos. No decorrer da vida, esta prevalência sobe para 10 a $20 \%$.

Segundo Simone de Beauvoir, em seu livro: “A Velhice”, as civilizações apresentam costumes variados no que tange aos cuidados com os idosos. Em geral, enquanto são robustos, vivazes, lúcidos, eles têm forte poder e influência dentro da população. Quando, entretanto, se tornam inseguros, inábeis, indefesos, doentes, decrépitos, são atirados à própria sorte.

Os habitantes do sul do Sudão, os "Dinka", honorificavam os seus anciãos, esteios da comunidade, enquanto se mostravam produtivos e sábios. Tão logo ameaçavam adoecer ou demonstrar fraqueza, eram simplesmente enterrados vivos (VERAS, 1994).

Entre os "Hetentote", seminômades da África, os indivíduos com 50 anos já eram considerados velhos. Paravam de trabalhar e passavam a ser sustentados pelos familiares. Tratados com reverência, suas opiniões continuavam a ser acatadas. Eram consultados por todos da comunidade, a qual auxiliavam a manter coesa. Quando suas capacidades diminuíam, a aldeia colocava-os no dorso de um boi e, depois da despedida, os levavam junto com uma tropa até um distante lugar onde havia uma choça. Com poucos alimentos e à mercê da sorte, acabavam morrendo de fome ou pelo ataque de animais ferozes (BOSI, 1995).

Os esquimós velhos, não produtivos, até hoje são abandonados na neve ou num iglu onde acabam morrendo de frio. Outros esquimós, da Groelândia, quando percebem o peso que estão representando para seus familiares, acabam suicidando-se.

Certas sociedades antigas, pelo contrário, veneram seus idosos até morrerem, proporcionandolhes uma morte justa e tranqüila. Assim era a civilização Inca, por exemplo.

Os habitantes de Bali costumavam antigamente sacrificar e comer seus anciãos. Em razão de determinadas ocorrências sociais imperativas, passaram a respeitá-los e idolatrá-los nos dias atuais.

Observamos pois, que dependendo da sociedade e dos seus costumes, os velhos são mal ou bem tratados. Antigamente se pensava que o Japão, considerado país dos velhos, cuidava bem dos anciãos. Na atualidade, sabe-se que, desde o pós-guerra, eles são, em geral abandonados em asilos governamentais. Em razão do filho mais velho não ter hoje a posse total da herança dos pais, o filho também não se sente mais na obrigação de cuidar do pai ou da mãe.

Id en line Revista de Psicologia. Ano 7, No. 21, Novembroo/2013 - ISSN 1981-1179.

Edição eletrônica em http://idonline.emnuvens.com.br/id 
Em um artigo de revisão recente, Frazer et al. (2005) sugerem que, dentre outros métodos, a atividade física pode ser considerada eficaz no tratamento da depressão. Atividade física é qualquer movimento corporal produzido pelos músculos esqueléticos que resulta em gasto energético maior do que o dos níveis de repouso. Já o exercício é uma atividade física planejada, estruturada e repetitiva, que tem como objetivo final ou intermediário aumentar ou manter a saúde/aptidão física (CASPERSEN, POWEL, CHRISTENSON, 1985). Tanto a atividade quanto o exercício podem propiciar benefícios agudos e crônicos. São eles: melhora no condicionamento físico; diminuição da perda de massa óssea e muscular; aumento da força, coordenação e equilíbrio; redução da incapacidade funcional, da intensidade dos pensamentos negativos e das doenças físicas; e promoção da melhoria do bem-estar e do humor (FOUNTOULAKIS, O'HARA, IACOVIDES, CAMILLERI, KAPRINIS, KAPRINIS G, et al,2003). Entretanto, os efeitos da prática de atividades físicas sobre a depressão ainda são contraditórios. Alguns estudos associam modificações nos quadros de depressão como resultantes da prática de atividades (FUKUKAWA, NAKASHIMA, TSUBOI, KOZAKAI, DOYO, NIINO, et al., 2004), enquanto outros trabalhos (STRAWBRIDGE, DELEGER, ROBERTS, KAPLAN, 2002; VAN GOOL, KEMPEN, PENNINX, DEEG, BEEKMAN, VAN, 2003) relacionam a prática mais freqüente de atividades à própria melhora na gravidade do transtorno depressivo.

A saúde física e mental do ser humano, depende de alguns fatores determinantes como: biologia humana, ambiente, estilo de vida, sistema de atendimento médico, etc. Para controlar os problemas que afetam a saúde, podemos adotar pelo menos três estratégias diferentes: A prevenção, a proteção e a promoção da saúde. No caso da prevenção, serão acionados uma série de procedimentos e atividades visando evitar-se a doença e impedir o seu desenvolvimento. Incluem-se aqui os serviços tradicionalmente associados a medicina clínica como imunizações e exames médicos de rotina. Os serviços de proteção à saúde abordam problemas, cujas soluções dependem principalmente do meio ambiente, como por exemplo: envenenamentos, intoxicações em locais de trabalho, saúde ocupacional, existência de normas de segurança, fluoretação da água, etc. Já os serviços de prevenção procuram alterar os comportamentos que afetam a saúde, expressos em hábitos nocivos.

Muitas doenças físicas ou psicossomáticas ocorrem ou são agravadas por hábitos pessoais prejudiciais, envolvendo ações voluntárias ligadas ao modo de vida de cada um.

Nesse contexto, nos indagamos: Como a literatura está relacionando a depressão e os programas de convivência de idosos, propostos por algumas prefeituras e organizações não governamentais?, e, até que ponto esses programas tem sido efetivos na redução da depressão em idosos?.

Este estudo se propôs a realizar um levantamento estatístico para analisar a influência da assistência Psicossocial aos idosos, como fator redutor de quadro depressivo, em um grupo de 112

Id en line Revista de Psicologia. Ano 7, No. 21, Novembroo/2013 - ISSN 1981-1179

Edição eletrônica em http://idonline.emnuvens.com.br/id 
idosos, com idade superior a 60 anos, assistido pelo Centro Social Urbano, na cidade de Barbalha/CE, no período de junho/10 a maio/11.

Dentro deste contexto consideramos: Faixa etária; Sexo; Situação Sócio-econômica; Condições de vida e moradia; Incidência de sintomas associados à depressão.

\section{Método}

Este trabalho foi realizado no período de junho/10 a maio/11, no Centro Social Urbano da Cidade de Barbalha/CE, às quartas e sábados, em conjunto com a equipe multidisciplinar que presta serviço no local.

Trata-se de um estudo descritivo, realizado á partir dos seguintes procedimentos:

a) Observação do número de idosos assistidos pelo Programa de Assistência ao Idoso, promovido pelo Centro Social Urbano, na cidade de Barbalha/CE, no período de junho/2010 a maio/2011.

b) Selecionar e observar os casos de depressão e outros com sintomas associados, indicativos de quadro depressivo.

c) Relacionar a depressão com a situação sócio-econômica, faixa etária, estado civil, condições de vida e moradia desses idosos.

Os dados foram coletados através da anamnese médica, questionário sócio-econômico e Questionário de avaliação da motivação para a depressão. O número total da amostra foi de 112 idosos, com idades à partir de 60 anos e constituiu-se da totalidade dos que freqüentavam as atividades do Centro Social Urbano de Barbalha/CE.

Dentre os instrumentos utilizados, constaram: a) Um questionário sócio-econômico, com a intenção de obter informações sobre a situação sócio-econômica dos idosos, bem como condições de moradia, condições atuais de saúde, atividades sociais que participa, lazer predileto, etc, dentre outras que possam ajudar na formação do perfil dos que procuram participar das atividades promovidas pelo Centro Social Urbano de Barbalha; b) Um formulário de avaliação médica, que continha informações mais detalhadas sobre o estado de saúde do idoso.

Trata-se de uma anamnese onde constam, dentre outras informações, situação familiar, doenças pregressas, medicações utilizadas regularmente, hábitos alimentares, tiques, sono, humor, medos, conduta sexual, atitudes anti-sociais, etc; e um Questionário de Avaliação da Motivação para a depressão, com a intenção de investigar a incidência e a propensão do idoso para a depressão. Consta de uma série de perguntas, que dizem respeito ao seu humor, objetivos de vida, facilidade de fazer 
amigos, o que sente em relação à vida, etc. que deverão ser respondidas pelo próprio idoso . Este questionário também tem o objetivo de investigar a predisposição dos idosos para o suicídio. Este questionário será utilizado no início, durante a primeira anamnese e no final da pesquisa, como uma segunda anamnese.

\section{Resultados e Discussão}

Tabela1 - Condições de Moradia. Barbalha, 2011.

\begin{tabular}{l|c|c}
\hline \multicolumn{1}{c|}{ Condições de Moradia } & Total & Percentual (\%) \\
\hline 1. Sozinho & 37 & 33,0 \\
\hline 2. Com a Família & 61 & 54,5 \\
\hline 3. Com outras pessoas & 5 & 4,5 \\
\hline 4. Instituição/Abrigo & 9 & 8,0 \\
\hline 5. Na Rua & 0 & 0,0 \\
\hline
\end{tabular}

Fonte: Dados da pesquisa.

A Tabela 1 revela que, 45,5\% dos idosos inscritos no Programa de Assistência ao Idoso, não convive diretamente com a família, e que destes, $33 \%$ mora sozinho.

Sabemos que cada povo e cada cultura tem a sua visão sobre o envelhecer. Em algumas sociedades como a nossa, o idoso parece ser estigmatizado e destituído do seu valor, a despeito da bagagem de experiências que carrega.

Este percentual alarmante de idosos vivendo sozinhos, é indicativo de que além de indesejáveis, inúteis ou incômodos, parecem ser percebidos como culpados de complicar a vida de gerações mais novas. Algumas cidades Européias, tem sido palco de manifestações públicas de jovens contra trabalhadores idosos, que permanecendo em atividade, são vistos como causa de desemprego (WOLF, 2001). 
http://idonline.emnuvens.com.br/id ISSN on-line: 1981-1179

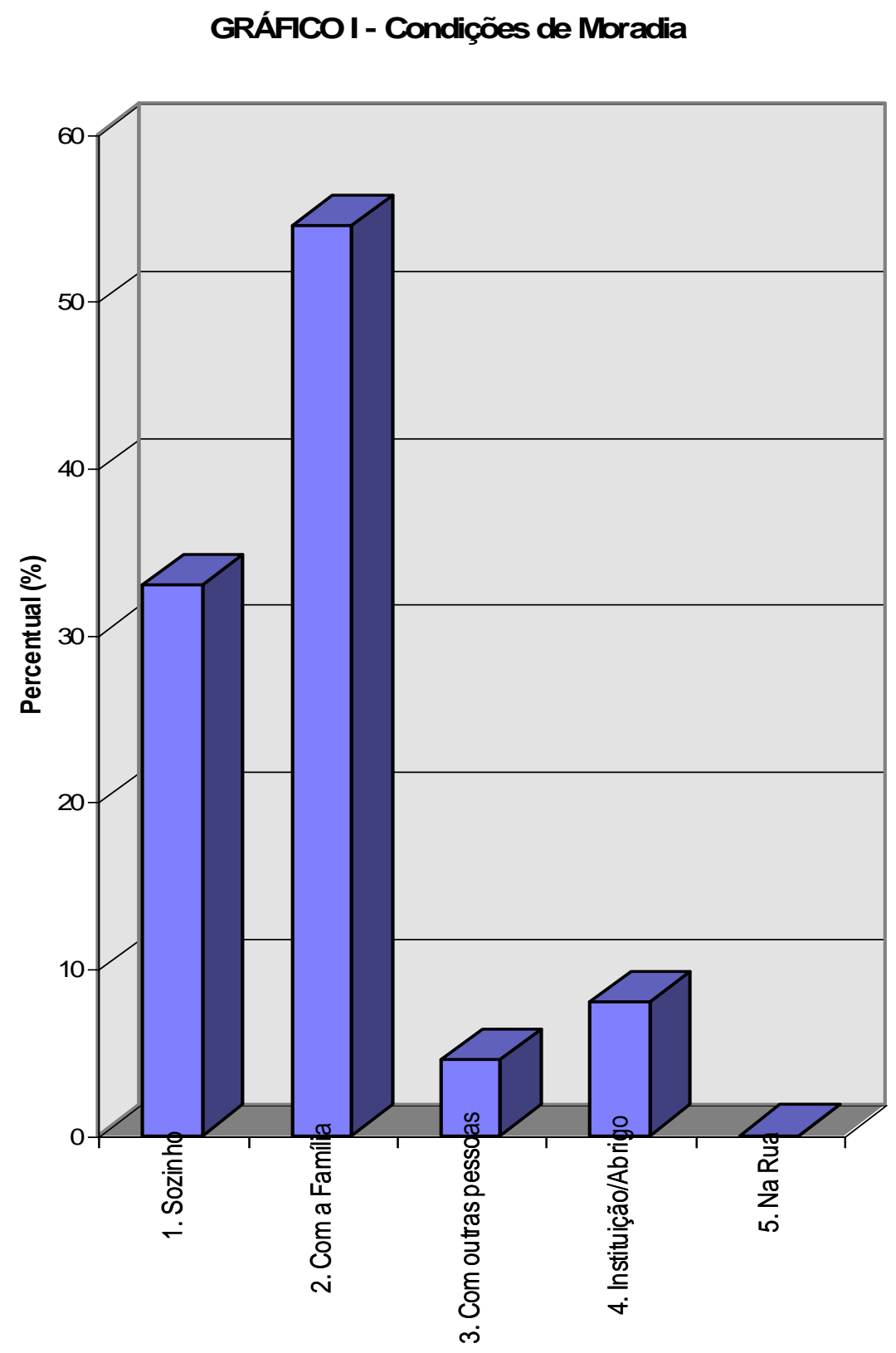


Tabela 2 - Renda Mensal. Barbalha, 2011.

\begin{tabular}{l|c|c}
\hline $\begin{array}{c}\text { Renda Mensal em } \\
\text { Salário Mínimo Vigente }\end{array}$ & Total & Percentual (\%) \\
\hline De 0,00 a 1 & 94 & 83,9 \\
\hline De 1,01 a 2 & 8 & 7,1 \\
\hline De 2,01 a 3 & 6 & 5,4 \\
\hline Maior que 3 & 4 & 3,6 \\
\hline
\end{tabular}

Fonte: Dados da pesquisa

A Tabela 2 mostra que as pessoas de terceira idade, assistidos pelo Programa de Assistência ao Idoso no Centro Social Urbano de Barbalha, é pobre, uma vez que a grande maioria 83,9\% não possui renda ou percebe até um salário mínimo de renda mensal.

Muitos idosos sentem-se abandonados ou desprezados por suas famílias, quando aposentamse, ou não podem cumprir um papel significativo financeiramente. Infelizmente, a maioria das ações governamentais tem uma natureza essencialmente assitencialista, objetivando apenas suprir algumas carências básicas da população. A filosofia da política para este segmento da sociedade confunde-se com caridade, pois atentam, exclusivamente, à manutenção biológica do idoso.

É necessário que se considere a subsistência material e a dignidade pessoal do idoso, com suas necessidades básicas, em consonância com a Declaração Universal dos Direitos Humanos. Que leve-se em conta a manutenção do nível de remuneração percebido quando em atividade; que se oportunize aos idosos a satisfação de suas necessidades culturais artísticas e de criatividade, como consumidor e produtor de cultura e que possa ser repensado o atendimento às necessidades afetivas, emocionais e psicológicas do idoso. 
http://idonline.emnuvens.com.br/id

ISSN on-line: 1981-1179

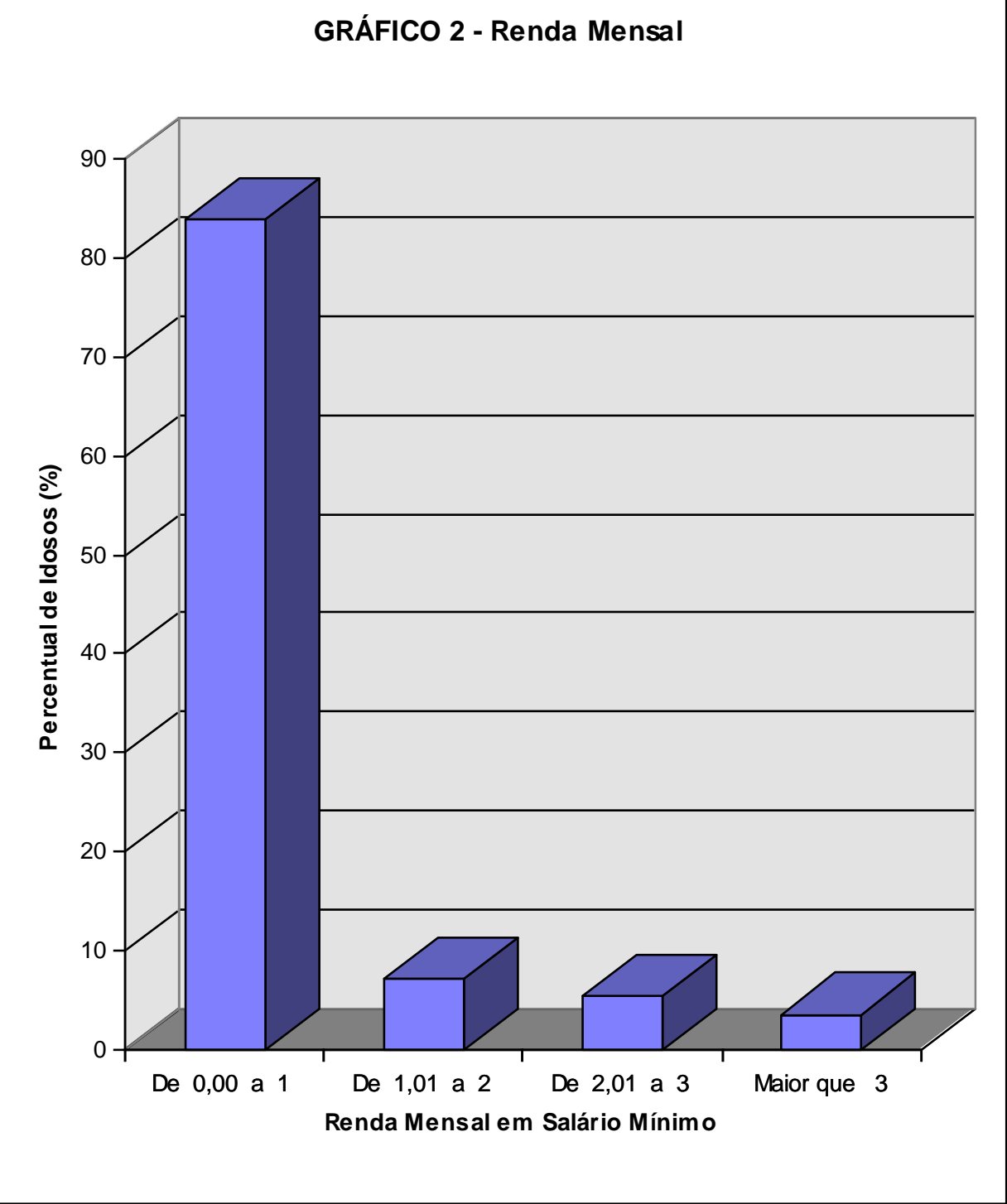


Tabela 3 - Faixa Etária e Sexo dos Idosos que freqüentam o Centro Social Urbano de Barbalha/CE, 2011.

\begin{tabular}{c|c|c|c|c|c|c}
\hline $\begin{array}{c}\text { Faixa } \\
\text { Etária }\end{array}$ & $\begin{array}{c}\text { Total de } \\
\text { Idosos }\end{array}$ & $\begin{array}{c}(\%) \\
\text { Total }\end{array}$ & Sexo Fem & $\begin{array}{c}(\%) \\
\text { Sexo Fem }\end{array}$ & Sexo Mas & $\begin{array}{c}(\%) \\
\text { Sexo Mas }\end{array}$ \\
\hline Até 60 & 5 & 4,5 & 4 & 3,5 & 1 & 0,9 \\
\hline 61 a 65 & 71 & 63,3 & 47 & 41,9 & 24 & 21,5 \\
\hline 66 a 70 & 15 & 13,4 & 11 & 9,8 & 4 & 3,5 \\
\hline 71 a 75 & 12 & 10,7 & 7 & 6,3 & 5 & 4,5 \\
\hline 76 a 80 & 6 & 5,4 & 3 & 2,7 & 3 & 2,7 \\
\hline 81 a 85 & 2 & 1,8 & 2 & 1,8 & 0 & 0,0 \\
\hline 86 a 90 & 1 & 0,9 & 0 & 0,0 & 1 & 0,9 \\
\hline$>$ que 90 & 0 & 0,0 & 0 & 0,0 & 0 & 0,0 \\
\hline Total & $\mathbf{1 1 2}$ & $\mathbf{1 0 0 , 0}$ & $\mathbf{7 4}$ & $\mathbf{6 6 , 0}$ & $\mathbf{3 8}$ & $\mathbf{3 4 , 0}$ \\
\hline
\end{tabular}

Fonte: Dados da pesquisa

Quanto à faixa etária, a grande maioria, 63,3\% estão na faixa de 61 a 65 anos, onde também existe uma grande concentração de mulheres (41,9\%). Apenas 4,5\% possui até 60 anos e 1,8\% dos idosos têm idade entre 86 e 90 anos. Quanto ao sexo, a maioria (66\%) são mulheres contra 34\% de idosos do sexo masculino.

Tabela 4 - Principais Sintomas Orgânicos Citados pelo entrevistados, na Avaliação Médica e no Questionário Motivação para a Depressão. Barbalha, 2011.

\begin{tabular}{l|c|c}
\hline Sintoma & $\mathbf{1}^{\mathbf{a}}$. Anamnese & $\mathbf{2}^{\mathbf{a}}$. Anamnese \\
\hline Insônia & 41 & 6 \\
\hline Dor de Cabeça & 28 & 6 \\
\hline Perda de Apetite & 19 & 7 \\
\hline Constripação Intestinal ou Diarréia & 15 & 5 \\
\hline Náuseas & 5 & 0 \\
\hline Sensação de Opressão no Peito & 21 & 5 \\
\hline Sensação de "Bolo" na Garganta & 4 & 1 \\
\hline Continua... & & \\
\hline
\end{tabular}




\begin{tabular}{l|c|c}
\hline Dificuldade de Respirar - Sensação de Falta de Ar & 25 & 7 \\
\hline Dor no Peito & 14 & 6 \\
\hline Sensação de "Falhas" no Coração & 16 & 2 \\
\hline Dores nas Costas & 45 & 17 \\
\hline Fadiga & 73 & 25 \\
\hline Perda/Redução do Apetite Sexual & 38 & 29 \\
\hline
\end{tabular}

Fonte: dados da pesquisa.

A Tabela 4 mostra o resultado do questionário de avaliação para a depressão. Na primeira anamnese, obtida quando do ingresso dos idosos nas atividades do Centro Social Urbano, demonstra uma grande tendência a um quadro depressivo. $65,2 \%$ dos pacientes que se apresentam com queixas diversas, desde fadiga até dificuldades de respirar, na verdade sofrem de depressão. Dos idosos que apresentaram sintomas associados a quadro depressivo, $12 \%$ apresentam depressão significativa.

Ao final de um ano, repetida a anamnese, observa-se uma sensível diminuição na queixa de sintomas indicativos de quadro depressivo.

Tabela 5 - Número de Idosos que Pensam em Suicídio. Barbalha, 2011.

\begin{tabular}{l|c|c|c|c|c|c|c|c}
\hline $\begin{array}{c}\text { Anamnes } \\
\text { e } \\
\text { Médica }\end{array}$ & \multicolumn{2}{|c|}{ Pensa } & \multicolumn{3}{|c|}{ em } & \multicolumn{2}{|c}{ Vuicídio } & \multicolumn{3}{|c}{ Sece } & \multicolumn{3}{|c}{ Mataria $~$} \\
\cline { 2 - 9 } & Sim & (\% Sim) & Não & (\% Não) & Sim & (\% Sim) & Não & (\% Não) \\
\hline Primeir & 16 & 14,3 & 96 & 85,7 & 10 & 62,5 & 6 & 37,5 \\
a & & & & & & & & \\
\hline Segund & 3 & 2,7 & 109 & 97,3 & 2 & 12,5 & 14 & 87,5 \\
a & & & & & & & & \\
\hline
\end{tabular}

Fonte: Dados da pesquisa.

A Tabela 5, demonstrou uma grande predisposição dos idosos (14,3\%, na primeira anamnese) para o suicídio. Isso nos leva a crer que à medida que o indivíduo vai avançando na idade, se aproximando da aposentadoria e se conscientizando de que não será mais produtivo, da forma que a sociedade exige, ele mesmo e os demais à sua volta, começam a fechar as chamadas "portas sociais". O indivíduo idoso torna-se então um inútil aos olhos da sociedade e como a improdutividade tecnológica é para nós, sinônimo de decadência, usufruir da vida, de modo prazeiroso, fica sendo para o idoso um sonho inatingível. 
Quando se aposenta, isso realmente se concretiza. Não terá mais a quem ensinar, com quem discutir pontos de vista, etc. Infelizmente este papel de "desocupado"mexe com o emocional e influencia sobremaneira, o comportamento do idoso. No caso do homem, parece ser mais grave do que nas mulheres, pois elas são quase que totalmente dedicadas ao lar e não sentem essa diferença social brutal.

Esta tabela também enfoca a questão da coragem de tirar a própria vida. Dos 16 idosos que pensam em suicídio, na primeira anamnese, $62,5 \%$ teria coragem de fazê-lo.

Os suicídios são muito freqüentes, embora o fator psicológico influencie bastante a tomada da decisão, também deve-se salientar a parcela de responsabilidade que cabe ao social nestes casos. Até que ponto vai o egoísmo e a cobiça da sociedade através das suas "alternativas" para afastar o idoso do convívio social e mesmo familiar. A visão negativa que se faz do geronto e que se transmite aos mais jovens distorcem sua imagem enquanto ser humano. Para muitos, ao que parece, isso é fator suficiente para uma auto-eliminação.

Costa (1989) esclarece que, o suicídio dos anciãos, em geral, dentro de uma aparente irracionalidade em suas motivações, é ainda assim, uma forma de antecipação, um último ato de realização livre e espontânea do indivíduo, no sentido de superar a sua angústia existencial. Uma tentativa de reconquistar alguma espécie de provir, frente a única experiência que ainda lhe resta, para encerrar sua existência.

Observa-se também uma melhoria significativa na predisposição para o suicídio na segunda anamnese, caindo para $2,7 \%$, quando o idoso enfim encontra alguém com quem compartilhar seus temores, suas alegrias e experiências.

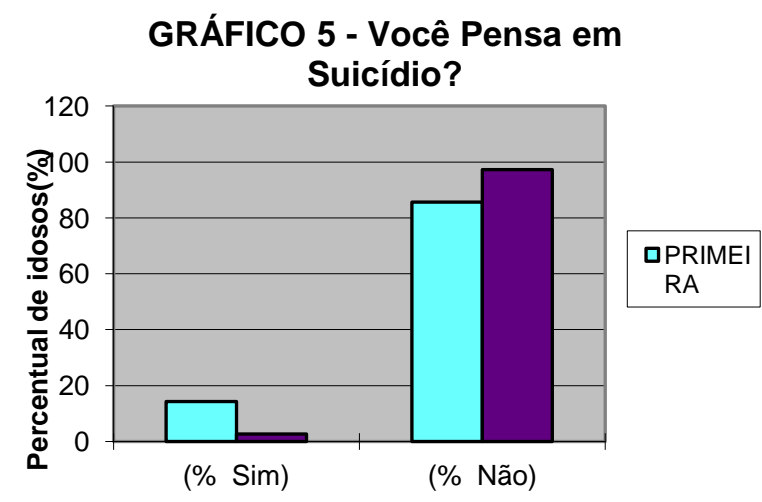




\section{GRÁFICO 6 - Você se Mataria?}

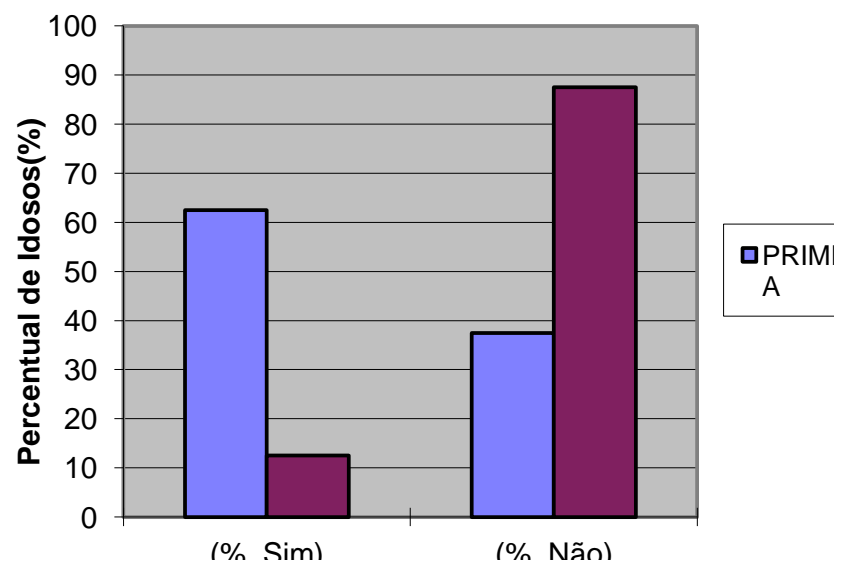

\section{Conclusões}

Os resultados obtidos na primeira e segunda anamneses médicas, demonstrados na Tabela 4, nos leva a crer que a Assistência Psicosocial oferecida pelo Centro Social Urbano de Barbalha/CE, diminuiu, em proporções significativas, grande parte dos sintomas associados a quadros depressivos, nos idosos que freqüentam suas atividades. Por generalização, estes resultados mostram que os centros de Assistência Social e de convívio, não sendo soluções ideais, prestam um serviço insubstituível, nos casos em que os velhos encontram-se sem socorro da família. Seja porque não tenha família, ou porque esta se ache impossibilitada de cumprir sua missão.

Nestes Centros encontram apoio de profissionais, realizam atividades produtivas, dançam e convivem, fazem amigos, trocam idéias e confidências, enfim, sentem-se aceitos, tornando suas vidas menos melancólicas, mais dignas e mais respeitadas. Recebem amor e carinho, o que melhora sensivelmente sua auto-estima, escapando assim de sintomas depressivos que comprometem sua saúde física e psíquica.

Sendo o isolamento nocivo às pessoas sob vários aspectos, e em especial aos idosos, norma tão reconhecida da Psicologia e Psiquiatria, a ponto de a cura das doenças mentais se confundir com a interação social dos doentes, e observando o grande número de sintomas associados a depressão, em grupo de idosos, onde $33 \%$ mora sozinho e $45,8 \%$ não convive diretamente com a família, conclui-se o quão errado está o hábito crescente da família "evitar"os velhos, enviando-os para asilos ou lares coletivos, onde são mantidos fora do ambiente em que sempre viveram e criaram relações de amizade. Por outro lado, os Programas Preventivos às patologias da velhice e ao isolamento social dos velhos, está longe do ideal. A família nem sempre é o grupo ideal de atenção para o idoso. O grupo familiar 
tem sofrido modificações profundas, sobretudo nos centros urbanos, o que determina a necessidade de um apoio de instituições sociais, que propiciem o seu desenvolvimento sócio-emocional. Trata-se da tentativa de se preservar a autonomia do idoso, favorecendo uma relação mais positiva deste com outros grupos etários, com o próprio grupo familiar e com a sociedade como um todo.

É lamentável a falta de humanismo da nossa sociedade. Observamos na nossa pesquisa, como nossa sociedade opta por soluções "fáceis" e pouco dignas. Até os velhos desamparados e sem família, devem sempre que possível ser assistidos em seu próprio meio, possibilitando-lhes condições mais dignas de cidadania.

A perda dos papéis sociais, consideradas de extrema importância dentro de nossa sociedade como: papel másculo e viril no homem, papel feminino e fértil na mulher; papel profissional; papel de chefe da família (tanto para o homem quanto para a mulher, conforme a função específica de cada um); papel ligado ao estado civil, particularmente no caso de viuvez; a perda do poder, do prestígio e do valor que esses papéis fornecem; o afastamento da atividade produtiva e a conseqüente diminuição da condição econômica para muitos, interferem sobremaneira na relação social e interpessoal do velho, com sua família e consigo mesmo. Chegado o momento da "aposentadoria" ou quando se vêem desempregados, inúteis, sentem-se em alguns casos na miséria social.

Este status de "inativo" e improdutivo, na nossa sociedade, é sinônimo de decadência, deficiência e até caduquice, levando o idoso a ter distorcida sua auto-imagem, possibilitando a instalação de quadro depressivo. A aposentadoria agrava a condição material da velhice. Atualmente $70 \%$ dos aposentados brasileiros recebem uma renda mensal de até 3 salários mínimos (Fonte: Associação Nacional de Gerontologia - ANG/1997).

Os resultados deste estudo nos leva a crer que, as questões mais agudas relacionadas ao idoso continuam sendo de ordem humanitária: Saúde, Habitação, Educação, Inexistência de espaço social e, acima de tudo, a precária condição econômica. Portanto, esta parcela da população necessita de urgentes políticas públicas mais eficazes, relacionadas as suas necessidades, no atual contexto brasileiro.

\section{Referências}

BOSI, Ecléa - Memória e Sociedade: Lembranças de Velhos - São Paulo, Companhia das Letras: 1995.

CAMPOS, Narino José - Os Anos Não Envelhecem - São Paulo, Edições Paulinas: 1984. 
CAMPOS, Juarez de Queiroz, et al. - Doutrina da Administração Sanitária - São Paulo: Editora Jotacê, 1995.

CASPERSEN CJ, POWEL KE, CHRISTENSON GM. Physical activity, exercise, and physical fitness: definitions and distinctions for health-related research. Public Health Rep. V.100. n.2. p.126$31,1985$.

COSTA, Jurandir Freire - Ordem Médica e Norma Familiar - Rio de janeiro, Edições Graal:1989.

DAVIDSON RJ, LEWIS DA, ALLOY LB, AMARAL DG, BUSH G, COHEN JD, et al. Neural and behavioral substrates of mood and mood regulation. Biol Psychiatry. V.52. n.6. p.478-502, 2002 .

FUKUKAWA Y, NAKASHIMA C, TSUBOI S, KOZAKAI R, DOYO W, NIINO N, et al. Age differences in the effect of physical activity on depressive symptoms. Psychol Aging. v.19. n.2. p.346-51, 2004.

FRAZER CJ, CHRISTENSEN H, GRIFFITHS KM. Effectiveness of treatments for depression in older people. Med J Aust. v.182. n.12. p.627-32, 2005.

FOUNTOULAKIS KN, O'HARA R, IACOVIDES A, CAMILLERI CP, KAPRINIS S, KAPRINIS G, et al. Unipolar late-onset depression: a comprehensive review. Ann Gen Hosp Psychiatry. v.2. n.1. p.11, 2003..

HOLLENBERG M, HAIGHT T, TAGER IB. Depression decreases cardiorespiratory fitness in older women. J Clin Epidemiol. V.56. n.11. p.111-7, 2003.

ORGANIZAÇÃO MUNDIAL DE SAÚDE. Relatório Mundial de Saúde, Banco de Dados. Genebra: Organização Mundial de Saúde, 1999.

. Global Forum for Health Research: The10/90 Report on Health Research. Genebra: Organização Mundial da Saúde, 2000.

Innovative Care for Chronic Conditions. Meeting Report, 30-31 Maio 2001, OMS/MNC/CCH/ 01.01. Genebra: Organização Mundial da Saúde, 2001. 
STRAWBRIDGE WJ, DELEGER S, ROBERTS REAP, KLAN GA. Physical activity reduces the risk of subsequent depression for older adults. Am J Epidemiol. V.156. n.4. p.328-34, 2002.

VAN GOOL CH, KEMPEN GI, PENNINX BW, DEEG DJ, BEEKMAN AT, VAN EJIK JT. Relationship between changes in depressive symptoms and unhealthy lifestyles in late middle aged and older persons: results from the Longitudinal Aging Study Amsterdam. Age Ageing. Psychiatry. V.32. n.1 p.81-7, 2003.

YAFFE K, BLACKWELL T, GORE R, SANDS L, REUS V, BROWNER WS. Depressive symptoms and cognitive decline in nondemented elderly women:a prospective study. Arch Gen Psychiatry. v.56. n.5. p.425-30, 1999.

VERAS, Renato P. - País Jovem com Cabelos Brancos. A Saúde do Idoso no Brasil - Rio de Janeiro, Relume/Dumará: 1994.

WORLD HEALTH ORGANIZATION. Envelhecimento ativo: uma política de saúde / World Health Organization; tradução Suzana Gontijo. - Brasília: Organização Pan-Americana da Saúde, 2005. 60p.: il.

WOLF, D.A. Population change: friend or foe of the chronic care system. Health Affairs V.20. n.6. p.28-42, 2001.

\section{Como citar este artigo (Formato ISO):}

FERNANDES, L.L..; BARROSO, M.L.; MARINHO, A.O.O.; ROLIM, S.G.; SILVA, B.S. Assistência Psicossocial como coadjuvante na redução da depressão em idosos. Id on Line Revista de Psicologia, Novembro de 2013, vol.1, n.21, p. 146- 164 ISSN 1981-1189. 